\title{
The Development of a Conceptual Framework and Model for Uncovering Meaning in Contemporary Print Advertising in Secondary Schools
}

\author{
Mary Ruth Smith
}

Introduction

Although we will not come in contact with most of the 250 million people in our nation, we do share the same language and the same visual environment. We live in an age of pervasive mass communication resulting in the simultaneous exposure of a large number of people to the same visual stimuli from organized media sources. Increased literacy, greater affluence and advances in communications technology have caused mass media images to be readily available and within easy reach of every segment of society (Dennis, Ismach, \& Gillmour, 1978). Consequently, a profusion of visual images of all kinds surrounds us. They permeate every aspect of our society from morning until night. As such, they hold and maintain a prominent position in today's world and therefore, exert a persuasive influence on our society. They manage to evoke a tremendous influence over human affairs. According to Stein (1979), people have let mass media images "magnetize and addict them during almost every actlvity-eating, drinking, driving, sleeping, worshipping, politicking, and even dying" (p. ix).

A great many of these images are of a commercial nature. America's consuming society runs on desire and the mass media are instrumental in transforming common objects-from peanut butter to political candidatesinto signs of all the things which it covets most (Solomon, 1980). With this proliferation of artfully designed and message-oriented mass media images, it seems appropriate for art education curricula, which fundamentally deal with visual imagery, to prepare students to become informed participants in today's high tech visual society.

In this light, the purpose of this study was to develop a conceptual framework and instructional model leading secondary school students to uncover overt and subtle meanings in contemporary print advertising. In order to address the problem, the researcher is developing a conceptual framework and instructional model that will allow students to apply qualitative thinking strategies to the understanding of print media. It was perceived, in the hermeneutic sense, that educational criticism structures were appropriate for developing this larger educational structure because of their utilization of multiple thinking and inquiry strategies. 


\section{Context, Justification, and Significance of the Problem}

Students, who are viewed by commercial interests as present and future consumers, need to be taught how to uncover meaning in consumeroriented mass media images. The more they understand how these images operate, the more prepared they will be to control their highly persuasive influence. Bercsi (1987) advocates turning what she calls "media bombardment" and "sensory overload" into positive teaching challenges. For example, she thinks that students can be taught to have a "critical and selective eye" by "looking at mass-media images and deciphering the visual means and messages portrayed and then relating these experiences to current trends" prevalent in society (pp. 23-24). Berger (1989) maintains that it is important to teach students how to read and/or interpret various forms of visual communication, even the extremely complex printed advertising image. Kauppinen (1987) contends that it is necessary for art education to provide activities which will teach students about the ever-present visual images that carry convincing messages. For instance, she recommends that students critically analyze both visual and verbal elements in mass media images as well as present their findings in appropriate studio experiences.

In The Educational imagination, Eisner (1985) includes what he calls the vernacular arts as an area of useful study for today's students. He states that the vernacular arts contain what Vance Packard called "the hidden persuaders" (Eisner, 1985, p. 104). These hidden persuaders are visual images designed with skill to hit the viewer with full force to motivate him/her to do or not to do certain things. Eisner (1985) concludes that the "study of such arts would, at least in principle, help develop a level of critical consciousness that is now generally absent in our culture" (p. 104).

Present and past models used for the teaching of advertising art and design place emphasis on the "how to" approach in the formulation of learning activities. An example of this type of traditional curriculum used for teaching advertising art and design is found in a recent publication entitled A Survival Kit for the Secondary Art Teacher (Hume, 1990). The projects in the section on advertising art focus on developing traditional skills: the thumbnail sketch, the layout of a billboard, the design of a package, and poster making. There are no planned activities that will aid students in uncovering meaning in the various advertising arts. According to Nadaner (1985), this type of traditional art curriculum is "not the kind of curriculum that helps learners deal with the contemporary visual culture" (p. 11).

A review of literature (Smith, 1989a, 1989b) shows that the study of mass media images and their power over our feelings, actions, and attitudes occupies only a minute part of a few existing educational programs. In fact, it seems the need to be visually literate and in command of the influences of mass media images is rarely considered a priority in today's educational processes. On the other hand, current literature supports the belief that education can include some aspect of mass media images as an essential

Working Papers in Art Education 1992 
and necessary facet in teaching students to interpret, understand, and ultimately use these images in meaningful art experiences and activities (Chapman, 1978, 1982; Feldman, 1970; Bercsi, 1987; Bersson, 1986; Cawelti, 1976; Doherty, 1988; Duncum, 1987; Kauppinen, 1987; Nadaner, 1985; Eisner, 1985; Greh, 1984), Anderson (1990) does provide a framework for examining the meanings in environmental advertising, but it is only a skeleton structure consisting of suggestions for inquiry rather than the content of meaning. In short, in spite of the fact that many art educators advocate the development of curriculum materials and the teaching of media and advertising awareness, there are very few models available for such instruction and those that are available tend to focus on the development of technical skills, compositional formats, and product development.

Because of its eclectic nature within the area of visual studies, art education can be the content field of study that provides the format for the study of media images. Within that arena, this study focuses on the conceptual foundations and strategies for helping secondary school students identify, analyze, and interpret not only the forms of print advertising, but also their underlying meaning structures, resulting in a conceptual framework and model for instruction.

\section{Research Methodology}

Inductive analysis, as a qualitative method of research, is particularly conducive for discovering information or data without unreasonably imposing presuppositions on the problem under study (Patton, 1990). At the same time, a developing connoisseurship (Eisner, 1991) on the part of the researcher, aids her "to make fine-grained discriminations among complex and subtle qualities" (p. 63) in the information gleaned from the review of literature. In analyzing the data for significant content, a "rightness of fit" (Goodman, 1978) is established, applying the appropriate information from the literature review to the conceptual framework and instructional model for uncovering meaning in contemporary print advertising in secondary schools.

An initial review of literature provides data from multiple perspectives (Eisner, 1991) that are relative to the problem under study. First, an overview of advertising theory established advertising's philosophical foundations and reasons for being and its relationships to the methods it uses to portray visual imagery in a printed format. Second, theory addressing the development of qualitative thinking is reviewed. Third, and as an extension of number two, methods of pedagogical art criticism are examined to determine their effectiveness and potential appropriateness for developing critical thinking skills in secondary students as applied to the form and content of print advertising. Finally, theories of model building are reviewed with an eye toward their application in developing a teaching and learning framework at the secondary level based on pedagogical art criticism as a critical thinking strategy directed toward the content of print advertising. 
In this type of qualitative research the researcher, herself, is the research tool (Eisner, 1991; Patton, 1990). An accumulation of knowledge (Eisner, 1991) through the review of literature provided the researcher with a wealth of information to consider in the development of the conceptual framework and instructional model, the culminating product being designed to facilitate secondary students in uncovering overt and subtle meaning in print advertising. It was incumbent upon the researcher, as the research tool, "to go beyond the information given, to fill in the gaps, to generate interpretations, to extrapolate, and to make inferences in order to construe meaning" (Eisner, 1991 , p. 211). As she is constantly immersed in the subject matter of the literature review and the mechanisms of analysis and synthesis in sorting through the gathered information/data, the researcher is developing the necessary depth and sensitivity to make the keen distinctions required.

In justifying the qualitative method for this study, the following statement by Eisner (1991) is timely:

... it is as unreasonable as it is unwise to expect qualitative research ... to take on the kind of finality and specificity we often see in research ... using quantitative methods. The idea that one knows beforehand what the significant variables are and can predict their magnitude in ceils describing the anticipated effects of some treatment is simply inappropriate for qualitative research. This does not mean that there is no rhyme or reason to qualitative research, but rather that the course of its development is contingent upon the features of a future no one can fully anticipate. Qualitative inquiry requires a considerable faith that researchers will be sensitive to the significant and able to make the right moves in context. It means that the lines for the research will be less specific; more is left to opportunism and the adventitious. (p. 170)

Thus, the openness and flexibility of inductive analysis (Patton, 1990), as the utilized method of qualitative research, provided the direction and framework for the proposed study, the final product being an inquiry structure for secondary students to examine the overt and subtle messages of print advertising.

\section{References}

Anderson, T. (1990). Examining environmental advertising imagery through art education. The Journal of Social Theory in Art Education 10, 143-157.

Bercsi, C. L (1987). Awareness in action. Art Education 40 (11), 23-42.

Berger, A. A. (1989). Seeing is believing. Mountain View, CA: Mayfield. 
Bersson, R. (1986). Why art education lacks a social relevance: A contextual analysis. Art Education 4, 41-45.

Cawelti, J. G. (1976). Popular culture: Coming of age? Journal of Aesthetic Education $10(3 / 4), 162-182$.

Chapman, L. H. (1978). Approaches to art in education. NY: Harcourt Brace Javanowich.

Chapman, L. H. (1982). Instant art, instant culture: The unspoken policy for American schools. NY: Teachers College, Columbia University.

Dennis, E. E., Ismach, A. H., \& Gillmour, D. M. (1978). Enduring issues in mass communication. St. Paul, MN: West.

Doherty, T. (1988). Toward--and away from--an aesthetic of popular culture. Journal of Aesthetic Education 22, 31-44.

Duncum, P. (1987). What, even Dallas? Popular culture within the art curriculum. Studies in Art Education 29 (1), 6-16.

Eisner, E. W. (1985). The educational imagination (2nd ed.). NY: Macmillan.

Eisner, E. W. (1991). The enlightened eye. NY: Macmillan.

Feldman, E. B. (1970). Becoming human through art. Englewood Cliffs, NJ: Prentice-Hall.

Goodman, N. (1978). Ways of worldmaking. Indianapolis: Hackett.

Greh, D. (1984). Art education in the third wave. Art Education 37 (2), 40-41.

Hume, D. (1990). A survival kit for the secondary school art teacher. W. Nyack, NY: Center for Applied Research in Education.

Kauppinen, $H$. (1987). The contemporary image in art education. Art Education 39 (2), 38-45.

Nadaner, D. (1985). Responding to the image world: A proposal for art curricula. Art Education 37 (1), 9-12.

Patton, M. Q. (1990). Qualitative evaluation and research methods. London: Sage.

Smith, M. R. (1989a). A place for popular culture images in art education: A review of selected literature. (Unpublished working paper). 
Smith, M. R. (1989b). The consumer product advertising image in art education: A review of selected literature. (Unpublished working paper).

Solomon, J. (1988). The signs of our times: The secret meanings of everyday life. NY: Harper and Row.

Stein, J. W. (1979). Mass media, education, and a better society. Chicago: Nelson-Hall. 